\title{
Research on Supply Side Reform of China's Substantial Economy and Financial Industry Based on Cloud Computing Technology
}

\author{
Dr. Li Bahao \\ School of Economics and Management, Jiujiang College
}

Key words: supply-side reform, financial industry, business transform

\begin{abstract}
In the current process of China's economic development, Chinese government attaches great importance to the development of financial industry, and also promulgate related policies to promote the continuous reform of it. The reform of traditional financial business is relatively slow, and there are many problems in every aspect limiting the overall development of China's financial system. This paper first puts forward the research background of the supply-side reform research in the financial industry, and then analyzes the current problems. At last, it proposes the corresponding solutions for the reference of relevant personnel.
\end{abstract}

\section{Introduction}

Since the financial crisis in the early 21 st century, the entire world's economic system has undergone major changes. At present, the entire world's economic system has changed from the initial state. Under the current world economic system, in order to further improve China's overall development, the Chinses government proposes a corresponding supply-side reform strategy, which will comprehensively improve China's overall development. The supply-side reform strategy is closely related to the development of China's financial industry. Banks are the most important in the financial industry and the most relevant enterprises. Under the current changes of world economy, the development of China's banking enterprises has undergone major changes. Under the current situation, Chinese banks should continue to innovate. However, at present, China's banks have many problems in the process of reform, which limit China's overall development.

\section{Background of supply-side reform in China's financial industry}

The supply-side reform in the financial sector refers to the problems encountered in the process of reform in the financial industry. Under normal circumstances, the main problems in financial reform are reflected in the major contradiction between the old system structure and the new system structure. It is necessary to effectively deal with this, so as to improve the development efficiency of enterprises, ensure China's social and economic stability, and promote the overall development of the country. Supply-side reform is the main driving force for the development of large banks. It is in line with the current world economic system and can fully play its role and promote the overall reform of enterprises. From the relevant data, the current strategy is more suitable for China's financial industry system. It can effectively allocate the existing resources, help major enterprises to reduce the risks of reform, and constantly improve their own management system according to the overall situation, so that the enterprise can better adapt to the current economic development system ${ }^{[1]}$.

In recent years, the development of the banking business in China's financial industry has been unsatisfactory. After the launch of many businesses, most banks in China have used deposit profits and loan profits to promote the development of enterprises. This kind of operation has put some limits to the development of enterprises, and more seriously, it have greatly limited the overall development of our country. This paper makes a preliminary analysis of the current data, and deeply analyzes the problems in the financial industry under the current supply-side reform, and tries to offer corresponding solutions ${ }^{[2]}$.

From the large number of statistics in recent years, we can see that most of China's financial system is still in a good upward trend. According to its interest, cost, income and other business data, it can be seen that the growth rate of these items is different. Under the current world economic system, 
major financial industries should continue to increase their related businesses according to the income, so as to improve their comprehensive development ${ }^{[3]}$.

\section{The obvious problems in the financial industry's business transformation process}

(1) Business contradictions

At present, most of China's financial industry pays more attention to the development of its main business, and the proportion of main business is relatively high. From comparing the data of many banks, we can see that most banks are relying on interest to earn money, and other businesses occupy a relatively low proportion. This shows that there is a problem with their business allocation in the process of bank development. And the problem in the proportion of business occupation is very serious. At the current stage, China's economy is still in the process of rapid development, there are more and more types of enterprises, and its business projects are gradually increasing. Like the financial business released in previous years, the number of users rose to 90 million during one promotion activity, and the amount of income is 400 billion RMB. This economic benefit far exceeds the deposit profits of other financial industries. This has a great impact on the business development of the bank. For this reason, enterprises should allocate the occupation ratio of the business according to the current situation of the enterprise. How to manage the current project content of the enterprise is the main problem that the major financial industries should pay attention to ${ }^{[4]}$.

(2) The problem of gross contradiction

From the perspective of economic form, China has a large currency stock, but the overall capital development is not very satisfactory. China's economic development is relatively dependent on investment, and there is no better strategy for management now. China's money supply rate is relatively high, making excess capital flow. According to relevant data, although China's money supply is relatively sufficient, but due to the system, the currency ratio continues to decrease. In the current situation of excess capital flow, a lot of money is forced into savings, could not flow into the economic market. Due to the influence of many factors, some other financial enterprises lack of a large amount of funds for management. As a result, the overall investment is influential, the supply and demand of the economic system are seriously unbalanced. The gross contradiction problem is the major problem existed in the development of large financial industries ${ }^{[5]}$.

(3) The problem of structural contradiction

Inefficient supply will cause major problems in China's economic development. China's financial industry has a serious problems in its current configuration structure, which needs further optimization and improvement. Some traditional enterprises have an obvious excess phenomenon in the process of reform, resulting in the continuous increase of their debts, and the company's funds also have many problems. Those small and medium-sized enterprises with good potentials are unable to obtain help from other financial industries because of various factors. Their own economic benefits have big problems, which makes it difficult to obtain higher return, and their capital gains could not match the speed of economic development. How the current major financial industries optimize their own production structure is the main problem ${ }^{[7]}$.

(4) Problem of logical contradiction

At present, China's major financial industries are all in the seller's side. Most enterprises will adjust their own profits and improve some policies according to the current development situation, so as to ensure the positive returns of enterprises. The traditional financial industry product content could not meet the customers' current requirements. The customer pursues a diversified business. To this end, major financial industries should find their own corporate characteristics, and also find an effective economic model to carry out continuous reforms. Exclude some of the old traditional ideas, and rationally arrange staffing. Allocate some qualified and capable talents reasonably, give them a better space to play their roles, and at the same time change the traditional concerns of the enterprise. In the traditional enterprise system, most financial enterprises pay too much attention to the reputation risk of customers, and other business risks of the enterprise did not receive much attention. There are also some companies that only focus on the expansion of their own businesses, and continue to increase their business content, while not caring about the user's feelings and experience. Users who do not 
get a good experience and services will inevitably have dissatisfaction with the products, which will also have a negative impact on the society, and the business is difficult to develop. For this reason, relevant enterprises should provide good quality service to customers, which is the main content that most financial industries should pay attention to now. Enterprises should continue to improve management work according to their own operating models and processes. The management system should be re-planned if necessary, to ensure the overall development of the company.

\section{Effective countermeasures and related requirements for business transformation in the financial industry}

The transformation of financial enterprises is for the further development of enterprises, to improve their comprehensive strength and promote the economic development of society. Improving the revenue is the basic goal of most enterprises. In the process of reform, if there is a safe economic environment and a mature operating system, coupled with a reasonable economic structure, it can stimulate the rapid development of the financial industry, and these content and information is a necessary condition for the current financial industry reform. To this end, major financial enterprises should be clear about their own development, and carry out reforms based on a clear supply side, change totally from the internal distribution and resource allocation and related management of the enterprise, and transform the original single and passive modes. According to the company's own development and the current economic system, it should change continuously, thus to improve the original economic model. Especially in the current situation, China's scientific and technological development is relatively well, the information technology can optimize most of the financial industry's business, help companies establish a good management system, and improve the overall development of enterprises.

(1) Specific requirements for the transformation of the financial sector by the supply-side reform

Find the right transform direction for the enterprise. The content of the supply-side reform can clarify the current economic development path of China. Through the supply-side reform, major enterprises can see the current development situation of China's economy, so that they can control the development route according to the company's own business content, thus realizing the effective transformation of enterprises. The superior management staff of the enterprise should be clear about the definition of transformation. They can analyze other successful enterprises, and make adjustments through the experience of other enterprises' successful transformation. However, while learning from the experience, it is important to remember that the transformation content of others cannot be copied as a whole. They should make adjustments constantly according to the actual situation of their own enterprises, and they should also be brave in innovation and practice, thus helping enterprises to complete reforms and make comprehensive changes.

Serve the substantial economy. For now, China's economic development is relatively dependent on the development of the substantial economy. To this end, in the process of major enterprise reforms, we should use the supply side strategy to make adjustments. The major financial enterprises should pay attention to the development of China's substantial economy and related content and business. The relevant departments in China should also pay attention to the development of emerging industries in corporate finance, giving better support, and thus improving the effective development of the financial industry. Meanwhile, they should also continue to innovate the current financial business, thereby promoting the sustainable development of financial industry.

Do a good job in risk management and control. Major financial enterprises should start from the problems of their own enterprise projects and business content, find the main problems existing in the enterprise, and formulate corresponding strategies to increase risk control, pay attention to the current social economic mobility, especially the current market risk and operational risk. To this end, enterprises should: (1) do a good job in risk management, the company should increase the propaganda of internal management, and form a better risk management approach, thus helping enterprises to do their own internal management, and make a management manual based on the company's current development path, and gradually make the content concrete. (2) Build a good management organization and improve related systems. Let employees fully understand the specific 
situation of risk management and realize internal scientific management. (3) Accelerate the processing of innovative assets, verify relevant content, and make improvements according to the current economic form, continuously make adjustments according to the relevant content and market forms of some funds, solve the company's own problems, and then do the corresponding promotion work.

(2) Effective countermeasures for business transformation in the financial industry

Arrange the corresponding business content reasonably. The financial industry reform is for the overall development of its own business, and its main purpose is to improve its own economic returns. In the current development process, most financial enterprises have been hit by third parties, which has affected their own interests and profits, resulting in the falling of economic interest of most enterprises. To this end, the relevant financial industry should do a better job of service, improving their service quality to bring customers a good-quality experience. In the current rapid development of science and technology, computers can handle many complex content and services. For example, "cloud computing" can rationally arrange some businesses in banks and arrange the content of the business. In this way, the bank can reserve more business space and adjust other businesses to improve the company's own income. The financial industry can improve its own development structure through its own business optimization.

Improve the economic environment and the flow of funds and other related work. Constantly improving the company's economic system and optimizing the relevant environment are the main contents that the current financial industry should pay attention to. First of all, we should pay attention to the relevant content of the currency and adjust it according to the current economic development. Under the current economic form, China's monetary policy is relatively unsatisfactory. Major enterprises should break the original economic concept and improve the current passive situation. Secondly, formulate the corresponding regulatory strategy according to the current development form, and control the fund, but it cannot affect the operation of the enterprise itself, and it cannot interfere with the government, thereby improving the enterprise's proactivity, so that it can complete the corresponding flow of funds under supervision. Finally, improve the relevant legal provisions. Creating a better economic environment requires the protection of the legal system. The relevant enterprises must also pay attention to the cultivation of talents, and encourage talents to continue to innovate and reform.

Optimize the overall structure of the financial industry. At present, the overall structure of China's financial market is relatively simple, and there are obvious problems, and individual enterprises are treated unfairly. According to relevant data, in the current development process, financial enterprises should pay attention to the economic development trend of the society and continuously optimize their business structure according to the current social needs. At the same time, the government should pay attention to the supply of funds for emerging enterprises. Thus the hard power and service quality of the entity can be improved. On the other hand, from the perspective of the structural embodiment of the financial industry, relevant assessment systems are missing, and the business models need to be improved, thus the allocation of financial resources can be improved. Specifically, what should be done are changing the basic supervision system and lending institutions of its own enterprises, and at the same time continuing to standardize relevant business, serving the evaluation mechanism of the substantial economy, and improving the utilization rate of funds. On the other hand, the financial industry should continually innovate the model of its own enterprise, and at the same time formulate a corresponding management system, introduce relevant structures belonging to its own enterprise, continuously expand its own scale, and complete different types so that it can better match the current the economic system and reduce the risks of some emerging companies. Thus promoting their common development.

Focus on the overall development of the Internet. From the current development trend, in the future development process, the development of the financial industry will certainly be associated with the big data market, which is more conducive to the overall development of the enterprise. Major financial industries should pay attention to this issue and make full use of the Internet to improve the overall development of enterprises. At the same time, enterprises should use the Internet to establish 
a better financial awareness and use the Internet to establish a corresponding service platform, so that customers can use the platform to understand relevant financial business, their needs can be better met and their trust on companies can be improved. The management personnel of each enterprise should pay attention to this issue and actively carry out related business. At the same time, they should also pay attention to the development of online financial services. While implementing actual services, they should increase online business services and bring more high-quality services to customers. They would do a good job in all aspects of work, gradually improve personal work, and strengthen the competitiveness of banks. In addition, relevant companies should be good at using "cloud computing" and other related technologies to achieve creating part of the module, use calculations to realize retrieving, adding and deleting and other related functions, so that the customer-related data could be managed scientifically. According to the characteristics of current big data, we will continue to improve and furtherly find the needs of customers, gradually improved according to the customer's needs, and thus promoting the sustainable development of the financial industry.

Improve the reform mechanism of the financial industry. The reform of the financial industry requires the support of relevant state departments, using scientific and reasonable mechanisms to improve the content. The managers can carry out small operations according to the current form, and then accumulate good experience, which can reduce the problems existing in enterprise reform. Help enterprises to achieve transformation as soon as possible and promote better development of enterprises. In addition, information technology can be used to manage some of the current unfavorable factors and ensure the smooth reform of the enterprise.

\section{Conclusion}

In summary, in the current economic development process, China's financial industry is conducive to promoting China's overall economic development. However, according to the problems mentioned above, China's financial industry is facing many problems in the current reform process, which not only limits the development of the enterprise itself, but also hinders the overall development of the national economy. To this end, the corresponding management staff should use the "cloud computing" technology to improve the content, thereby promoting the sustainable development of the financial industry.

\section{References}

[1] Yao Yu'an. Talking about Internet Financial Application under Cloud Computing Technology [J]. Henan Science and Technology, 2015(02): 4-6.

[2] Pang Ling, Wu Hongle. Application Research of Cloud Computing Technology in Financial Statistics Information Platform [J]. Science and Technology Innovation, 2018(10): 66-67.

[3] Li Hongliang, Sun Mingdi, Xu Zheng. Analysis of Network Security Defense Technology under Cloud Computing Technology [J]. Electronic World, 2018 (22): 201.

[4] Du Jian. Research on the Current Dilemma and Future Development of Copyright_-Taking Cloud Computing Technology as the Research Perspective [J]. Publishing Science, 2014, 22(05): 55-60.

[5] Zuo Lin. Design and Research of Computer Network Security Storage System under the Background of Cloud Computing Technology [J]. Electronic Technology and Software Engineering, 2016(08):216.

[6] Zhao Zhichao, Wu Tiefeng. Design and Implementation of E-commerce Platform under Cloud Computing Technology [J]. Modernization of Shopping Malls, 2017(07): 60-61.

[7] Zhong Ruyan. Research on the New Model of Enterprise Configurable Human Resource Management Based on "Cloud Computing” [J]. Talent Resources Development, 2018(24): 87- 
88.

[8] Yang Zheng, Wang Hongjian, Dai Jing, Xu Chuanhua. Deregulation of Interest Rate Control, Equalization of Profit Rate and Entity Enterprises "Getting Away from Reality and Getting Close to Illusion" [J]. Financial Research, 2019 (06): 20-38.

[9] Cao Jie, Lei Lianghai. Risk Spillover Effects of Financial and Real Industry Based on Dynamic Generalized $\triangle$ CovaR Method [J]. Systems Engineering, 2019, 37(03): 122-131.

[10] Gao Jie. Exploring the Impact of China's Financial Development on the Real Economy [J]. Modern Marketing (Chuangfu Information Edition), 2018 (11): 147.

[11] Wang Shouyi. The Trend of Economic Financialization and Its Enlightenment to the Development of China's Real Economy_Based on the Analysis of American Economic Development Data from 1973 to 2017[J]. Marxism Research, 2018(10): 62-73.

[12] Yao Yong. The Trend of Economic Financialization and Its Enlightenment to China's Financial Development [J]. Chinese and Foreign Entrepreneurs, 2018(10): 57+60. 